\title{
Female gender and the clinical and periprocedural profile and clinical outcomes of transcatheter aortic valve implantation: experiences of a tertiary Polish centre
}

\author{
Krzysztof Wilczek ${ }^{1}$, Piotr Chodór ${ }^{2}$, Maciej Dyrbuś ${ }^{3}$, Michał Hawranek ${ }^{1}$, tukasz Włoch ${ }^{2}$, tukasz Pyka ${ }^{1}$, \\ Tomasz Hrapkowicz ${ }^{4}$, Michał Zembala ${ }^{4}$, Zbigniew Kalarus² ${ }^{2}$ Mariusz Gąsior ${ }^{1}$ \\ ${ }^{1} 3^{\text {rd }}$ Department of Cardiology, Faculty of Medical Sciences in Zabrze, Medical University of Silesia in Katowice, Poland \\ ${ }^{2}$ Department of Cardiology, Congenital Heart Diseases and Electrotherapy, Medical University of Silesia in Katowice, Silesian Centre for \\ Heart Diseases in Zabrze, Poland \\ ${ }^{3}$ Student Scientific Society, $3^{\text {rd }}$ Department of Cardiology, School of Medical Sciences in Zabrze, Medical University of Silesia in Katowice, \\ Poland \\ ${ }^{4}$ Department of Cardiac, Vascular, and Endovascular Surgery and Transplantology, Medical University of Silesia, Katowice, Poland
}

Adv Interv Cardiol 2020; 16, 4 (62): 436-443

DOI: https://doi.org/10.5114/aic.2020.101769

\begin{abstract}
A bstract
Introduction: Despite the establishment of multiple factors influencing short- and mid-term outcomes in patients treated with transcatheter aortic valve implantation (TAVI), the real-world data on the association between gender and outcomes after TAVI remain conflicting.

Aim: To evaluate the association of female gender with the clinical and periprocedural characteristics along with in-hospital, short- and medium-term outcomes of patients treated with TAVI in comparison with male patients.

Material and methods: Data from the prospective, single-centre registry of consecutive patients with severe AS referred for TAVI from 26 November 2008 to 31 December 2018 were analysed retrospectively. The study population comprised 275 patients who were divided by gender. The primary endpoint of the study was all-cause mortality at 1 year.

Results: Women constituted 132 (48.0\%) of the overall population. Women were significantly older, but had a significantly higher left ventricular ejection fraction (LVEF) and had less frequently undergone coronary artery bypass grafting (CABG) before TAVI. The implantation success rate was comparable between genders, but women less frequently required implantation of a pacemaker after TAVI, although they more frequently required blood transfusion due to severe bleeding. The primary endpoint occurred in $13.6 \%$ of women and $7.7 \%$ of men $(p=0.12)$.

Conclusions: Despite advanced age and prevalence of cardiovascular risk factors, the overall short- and medium-term mortality in patients treated with TAVI in our analysis of the real-world population remains relatively low. Although women seemed to have a slightly better clinical baseline profile, their in-hospital, 30-day, 6-month and 12-month outcomes did not differ significantly from the male patients.
\end{abstract}

Key words: mortality, gender differences, aortic stenosis, transcatheter aortic valve implantation, midterm outcome.

Su m m a ry

Although the influence of gender on the outcomes of patients treated with transcatheter aortic valve implantation (TAVI) has been analysed in multiple randomized trials and registries, there is still no certainty on their association. In our study, 275 patients who underwent TAVI in a tertiary cardiovascular centre were divided according to gender and compared with regard to characteristics and short- and mid-term outcomes. In the study, the post-TAVI outcomes did not differ significantly between genders ( $p$ log rank $=0.18$ ). Our analysis reflects the real-life practice, emphasizing that the availability and therapeutic schemes should be similar for men and women treated with TAVI in Poland.

Corresponding author:

Krzysztof Wilczek MD, PhD, $3^{\text {rd }}$ Department of Cardiology, Faculty of Medical Sciences, Medical University of Silesia, Zabrze, Poland,

e-mail:wilky@poczta.onet.pl

Received: 10.06.2020, accepted: 12.10 .2020 . 


\section{Introduction}

Since the introduction of transcatheter aortic valve implantation (TAVI) into clinical practice in 2002, the strategy of treatment for severe aortic stenosis (AS) has seen a dramatic diversion from the open-heart surgical valve replacement towards less invasive, transcatheter intervention. The large randomized trials and registries have demonstrated that TAVI is feasible and safe in patients with high- or medium surgical risk, which has been recently confirmed in the low-risk population the low-risk population as well [1-4]. Therefore, with a wider adoption of less invasive, more minimalistic strategies of TAVI, the number of TAVI procedures performed each year will see a significant growth in the next years [5].

Despite the identification of multiple risk factors for worse outcomes after TAVI, the impact of gender is still debatable, mostly due to the large discrepancy between the published studies and the analysed populations [6-8].

\section{Aim}

The aim of this study was to assess the differences in the clinical and periprocedural characteristics between women and men undergoing TAVI in a tertiary Polish centre over a period of more than 10 years and evaluate the presence of possible differences in outcomes between them

\section{Material and methods}

Data from a prospective, single-centre registry of consecutive patients with severe AS referred for TAVI from November 2008 to December 2018 were analysed retrospectively. The primary aim of the registry is to assess the outcomes of all patients treated with TAVI in our facility as far as safety, efficacy and cost-effectiveness are concerned. The details of the registry have been presented in previously published manuscripts [9-12].

In brief, all patients included in the registry were hospitalized in a tertiary cardiovascular centre with cardiac surgery department due to echocardiographically determined severe symptomatic AS with aortic valve area (AVA) of $<1 \mathrm{~cm}^{2}$ and/or $<0.6 \mathrm{~cm}^{2} / \mathrm{m}^{2}$. The decision for the referral to the TAVI was based on either high surgical risk (> 20\% according to the Logistic EuroSCORE and/or $>10 \%$ according to the Society of Thoracic Surgeons (STS) score) or other comorbidities that deemed the patient inoperable. Hence, the registry included patients with lower surgical risk as well, but with comorbidities not included in the risk scores. Such cofactors included porcelain aorta or previous radiotherapy of the thorax and were assessed by the Heart Team.

The TAVI was performed in the Cardiac Catheterization Laboratory or Hybrid Operating Theatre depending on the discretion of the operators and the valve was implanted either via transfemoral, transapical, trans-subclavian or direct aortic access. The majority of transfemoral access procedures were performed under local anaesthesia with conscious sedation and vascular closure devices. The remaining transfemoral procedures and all procedures performed via other accesses were carried out in general anaesthesia. The procedures were performed as a routine TAVI as described elsewhere [13]. Before the procedure, the Heart Team discussed the optimal approach including the necessity for balloon aortic valvuloplasty (BAV) as a bridge to TAVI or percutaneous coronary intervention $(\mathrm{PCl})$ for the complex treatment of coronary artery disease (CAD) before TAVI. The primary endpoint of the study was all-cause mortality at 1 year from the procedure.

The definitions were established in accordance with the VARC-2 criteria [14]. Severe bleeding was identified as causing the loss of haemoglobin by more or $3 \mathrm{~g} / \mathrm{dl}$ or requiring transfusion or bleeding constituting the significant risk of harm at the discretion of the clinician in charge.

The demographic, baseline clinical, and angiographic data collected during hospitalization were obtained from our institutional database. The follow-up data with accompanying exact dates of death and NYHA functional status were obtained at the routine visits after TAVI conducted at 30 days, 6 months and 12 months in the outpatient clinic.

\section{Statistical analysis}

The statistical analysis includes the comparison of baseline clinical and periprocedural characteristics, and the 30-day, 6-month and 12-month adverse events. The analysed variables are expressed as numbers and percentages. The normality of the distribution was assessed using the Shapiro-Wilk test and the continuous variables were summarized using the arithmetic mean with standard deviation for data following normal distribution or the median with the first and third quartile for data demonstrating a non-normal distribution. Categorical variables were presented using frequency tables for both absolute numbers and percentages. If the distribution was normal, Student's $t$-test was used for independent or dependent values, and for the comparison of non-normally distributed variables the Mann-Whitney U-test was performed. The differences between the qualitative parameters were assessed using the $\chi^{2}$ test with Yates's correction, and Fisher's exact test if the analysed populations were insufficiently represented.

The cumulative death rates were analysed using the Kaplan-Meier method with the log-rank test performed to compare the survival curves between genders. A two-sided $p$-value $\leq 0.05$ was considered significant. The Statistica 10 (StatSoft Inc., Tulsa, Oklahoma) software was used for all calculations.

\section{Results}

Between November 2008 and December 2018, 382 TAVI procedures were performed in our facility, of which 
Table I. Clinical characteristics of the analysed population according to gender

\begin{tabular}{|c|c|c|c|c|}
\hline Parameter & Overall & Women & Men & $\begin{array}{l}P \text {-value } \\
\text { (women } \\
\text { vs. men) } \\
\end{array}$ \\
\hline $\begin{array}{l}\text { Age, median [Q1-Q3] } \\
(n / N)\end{array}$ & 79 [73-83] (275/275) & $80[74-84](132 / 132)$ & 77 [72-82] (143/143) & 0.001 \\
\hline $\begin{array}{l}\mathrm{BMI}\left[\mathrm{kg} / \mathrm{m}^{2}\right] \\
\text { median [Q1-Q3] }(\mathrm{n} / \mathrm{N})\end{array}$ & $27.1[24.2-31.1](270 / 275)$ & $27.0[22.6-31.2](130 / 132)$ & $27.3[25.3-30.8](141 / 143)$ & 0.08 \\
\hline $\begin{array}{l}\text { BSA [m²], } \\
\text { median [Q1-Q3] }(n / N)\end{array}$ & 1.84 [1.70-1.99] (270/275) & 1.76 [1.65-1.91] (130/132) & $1.90[1.78-2.01](140 / 143)$ & 0.001 \\
\hline $\begin{array}{l}\text { Logistic EuroSCORE \%, } \\
\text { median [Q1-Q3] }(n / N)\end{array}$ & $23.3[13.2-33.3](263 / 275)$ & $22.1[13.4-30.3](128 / 132)$ & 24.0 [12.0-36.9] (135/143) & 0.67 \\
\hline $\begin{array}{l}\text { STS \%, median [Q1-Q3] } \\
(n / N)\end{array}$ & $5.0[3.4-7.6](137 / 275)$ & $5.7[3.7-9.4](64 / 132)$ & $4.5[3.0-6.8](73 / 143)$ & 0.02 \\
\hline $\begin{array}{l}\text { NT-proBNP, } \\
\text { median [Q1-Q3] }(n / N)\end{array}$ & $2041.5[797.0-4018.0](250 / 275)$ & $1698.0[797.0-3422.0](119 / 132)$ & $2276.0[764.0-5363.0](131 / 143)$ & 0.21 \\
\hline $\begin{array}{l}\text { 6-MWT [m], } \\
\text { median [Q1-Q3] }(n / N)\end{array}$ & $245.5[126.0-315.0](193 / 275)$ & 189.0 [106.4-275.3] (94/132) & $284.0[186.0-325.0](99 / 143)$ & $<0.001$ \\
\hline Smokers \% $(n / N)$ & $32.0(84 / 262)$ & $14.4(18 / 125)$ & $48.1(66 / 137)$ & $<0.001$ \\
\hline Diabetes \% $(n / N)$ & $46.5(127 / 273)$ & $49.6(65 / 131)$ & $43.7(62 / 142)$ & 0.32 \\
\hline Hypertension \% $(n / N)$ & $80.1(220 / 272)$ & $84.7(111 / 131)$ & $77.3(109 / 141)$ & 0.11 \\
\hline $\begin{array}{l}\text { eGFR [ml/min/1.73 m²], } \\
\text { median [Q1-Q3] }\end{array}$ & $57.6[45.0-65.0](232 / 272)$ & $55.0[43.0-62.5](109 / 132)$ & $60.0[49.5-65.8](123 / 142)$ & 0.06 \\
\hline Prior MI \% $(n / N)$ & $35.3(96 / 272)$ & $32.1(42 / 131)$ & $38.3(54 / 141)$ & 0.28 \\
\hline NYHA I \% $(n / N)$ & $2.3(6 / 266)$ & $1.6(2 / 138)$ & $2.9(4 / 138)$ & 0.14 \\
\hline NYHA II \% $(n / N)$ & $34.2(91 / 266)$ & $30.5(39 / 128)$ & $37.7(52 / 138)$ & \\
\hline NYHA III \% $(n / N)$ & $56.4(150 / 266)$ & $60.2(77 / 128)$ & $52.9(73 / 138)$ & \\
\hline NYHA IV \% $(n / N)$ & $7.1(19 / 266)$ & $7.8(10 / 128)$ & $6.5(9 / 138)$ & \\
\hline $\begin{array}{l}\text { Prior aortic surgery } \\
\%(n / N)\end{array}$ & $6.1(15 / 245)$ & $5.1(6 / 117)$ & $7.0(9 / 128)$ & 0.60 \\
\hline $\begin{array}{l}\text { Prior PPM implantation } \\
\%(n / N)\end{array}$ & $18.1(48 / 265)$ & $13.5(17 / 126)$ & $22.3(31 / 139)$ & 0.08 \\
\hline $\mathrm{AF} \%(n / N)$ & $33.0(84 / 253)$ & $29.1(35 / 120)$ & $36.8(49 / 133)$ & 0.23 \\
\hline Prior CABG \% $(n / N)$ & $34.6(93 / 269)$ & $18.6(24 / 129)$ & $49.3(69 / 140)$ & $<0.001$ \\
\hline $\begin{array}{l}\mathrm{PCl} \text { in the last } 3 \text { months } \\
\%(n / N)\end{array}$ & $21.6(56 / 259)$ & $21.6(27 / 125)$ & $21.6(29 / 134)$ & 0.99 \\
\hline Prior stroke \% $(n / N)$ & $10.0(26 / 259)$ & $7.2(9 / 125)$ & $12.7(17 / 134)$ & 0.15 \\
\hline $\begin{array}{l}\text { LVEF, \% median [Q1-Q3] } \\
(n / N)\end{array}$ & $50.0[38.0-55.0](260 / 275)$ & $52.0[45.0-55.0](125 / 132)$ & $46.0[32.0-54.0](135 / 143)$ & $<0.001$ \\
\hline $\begin{array}{l}\left.\text { AVA [ } \mathrm{cm}^{2}\right] \\
\text { median [Q1-Q3] }(n / N)\end{array}$ & $0.69[0.50-0.80](238 / 275)$ & $0.60[0.50-0.78](106 / 132]$ & $0.70[0.55-0.80](132 / 143)$ & 0.004 \\
\hline $\begin{array}{l}\text { Annulus diameter TTE } \\
\text { [mm], median [Q1-Q3] } \\
(n / N)\end{array}$ & $23.0[21.0-24.5](207 / 275)$ & $21.0[20.00-23.00](95 / 132)$ & $24.0[22.0-25.0](112 / 143)$ & $<0.001$ \\
\hline $\begin{array}{l}\text { Annulus diameter TEE } \\
{[\mathrm{mm}], \text { mean } \pm \mathrm{SD}(n / N)}\end{array}$ & $23.3 \pm 2.4(96 / 275)$ & $22.0 \pm 1.6(41 / 132)$ & $24.3 \pm 2.5(55 / 143)$ & $<0.001$ \\
\hline $\begin{array}{l}\text { Max Ao velocity [m/s], } \\
\text { median [Q1-Q3] }(n / N)\end{array}$ & $4.26[3.82-4.70](112 / 275)$ & $4.20[3.66-4.70](57 / 132)$ & $4.34[3.90-4.70](55 / 143)$ & 0.40 \\
\hline $\begin{array}{l}\text { TG mean [mm Hg], } \\
\text { median [Q1-Q3] }(n / N)\end{array}$ & $45[37-56](245 / 275)$ & 46 [40-59] (114/132) & 45 [34-55] (131/143) & 0.11 \\
\hline $\begin{array}{l}\text { Mitral regurgitation } \\
\text { (moderate to severe) } \\
\%(n / N)\end{array}$ & $26.6(64 / 241)$ & $33.0(38 / 115)$ & $0.6(26 / 126)$ & 0.04 \\
\hline
\end{tabular}


275 with detailed clinical, periprocedural and postprocedural data were available for this analysis. Women constituted $48.0 \%$ of the overall population, while men comprised the remaining $52.0 \%$ of patients. There were significant differences between genders in terms of clinical characteristics (Table I). Women were significantly older, had smaller body surface area, and a significantly higher STS surgical risk score. Moreover, before the procedure, their exercise capacity measured in the 6-minute walk test was significantly worse than in men.
In contrast, $48.1 \%$ of men were active or former smokers and $49.3 \%$ of men had undergone CABG prior to TAVI. The average left ventricular ejection fraction (LVEF) value was on average $6 \%$ higher in women, while the median AVA was significantly lower. No other significant clinical differences were observed between the groups.

There were no differences in the vascular access route between genders, with $65.1 \%$ of all procedures performed transfemorally (Table II). Moreover, there were no differences in the location of the procedures, as $57.4 \%$ of

Table II. Periprocedural characteristics of the analysed population according to gender

\begin{tabular}{|c|c|c|c|c|}
\hline Parameter & Overall & Women & Men & $\begin{array}{c}P \text {-value } \\
\text { (women vs. } \\
\text { men) }\end{array}$ \\
\hline \multicolumn{4}{|l|}{ Vascular access, \% $(n / N)$ : } & 0.34 \\
\hline Transapical access & $20.4(52 / 255)$ & $24.0(29 / 121)$ & $17.2(23 / 134)$ & \\
\hline Transaortic access & $4.3(11 / 255)$ & $5.0(6 / 121)$ & $3.7(5 / 134)$ & \\
\hline Transfemoral access & $65.1(166 / 255)$ & $62.0(75 / 121)$ & $67.9(91 / 134)$ & \\
\hline Surgical femoral access & $30.1(50 / 166)$ & $38.7(29 / 75)$ & $23.1(21 / 91)$ & 0.041 \\
\hline \multicolumn{4}{|l|}{ Valve type, \% $(n / N)$ : } & 0.006 \\
\hline Edwards Sapien (any generation) & $13.4(42 / 275)$ & $19.7(26 / 132)$ & $11.2(16 / 143)$ & \\
\hline Boston Acurate & $29.5(81 / 275)$ & $34.1(45 / 132)$ & $25.2(36 / 143)$ & \\
\hline Medtronic CoreValve (any generation) & $55.3(152 / 275)$ & $46.2(61 / 132)$ & $63.6(91 / 143)$ & \\
\hline \multicolumn{4}{|l|}{ Location of the procedure: } & 0.94 \\
\hline Cath lab, \% $(n / N)$ & $42.6(120 / 275)$ & $44.0(58 / 132)$ & $42.0(62 / 143)$ & \\
\hline Hybrid room, \% $(n / N)$ & $57.4(162 / 275)$ & $59.8(79 / 132)$ & $58.0(83 / 143)$ & \\
\hline BAV performed, $\%(n / N)$ & $87.3(227 / 260)$ & $89.6(112 / 125)$ & $85.2(115 / 135)$ & 0.29 \\
\hline Sheath size [mm], median [Q1-Q3] (n/N) & $18[14-18](255 / 260)$ & $18[14-18](123 / 125)$ & $18[17-18](132 / 135]$ & 0.99 \\
\hline \multicolumn{4}{|l|}{ Vessel closure technique, \% $(n / N)$ : } & 0.11 \\
\hline Additional manual compression & $7.3(18 / 244)$ & $8.4(10 / 118)$ & $6.4(8 / 126)$ & \\
\hline Surgical closure & $49.1(120 / 244)$ & $53.3(63 / 118)$ & $42.9(54 / 126)$ & \\
\hline Vascular closure device & $43.4(106 / 244)$ & $38.1(45 / 118)$ & $48.4(61 / 126)$ & \\
\hline Implantation success & $96.8(242 / 250)$ & $95.0(115 / 121)$ & $98.5(127 / 129)$ & 0.13 \\
\hline $\begin{array}{l}\text { Pacemaker implantation necessity during index } \\
\text { hospitalization }\end{array}$ & $16.0(44 / 275)$ & $11.3(15 / 132)$ & $20.2(29 / 143)$ & 0.049 \\
\hline Puncture site complications & $5.0(12 / 238)$ & $7.1(8 / 112)$ & $3.2(4 / 126)$ & 0.24 \\
\hline Angiographically assessed regurgitation (any) & $50.4(122 / 242)$ & $46.2(54 / 117)$ & $54.4(68 / 125)$ & 0.199 \\
\hline Bailout surgical procedure & $0.84(2 / 238)$ & $1.8(2 / 112)$ & $0(0 / 126)$ & 0.19 \\
\hline Periprocedural MI & $0.8(2 / 250)$ & $1.65(2 / 121)$ & $0(0 / 129)$ & 0.23 \\
\hline Periprocedural stroke & $0.8(2 / 250)$ & $0.8(1 / 121)$ & $0.8(1 / 129)$ & 0.74 \\
\hline AF & $27.2(63 / 169)$ & $25.9(28 / 108)$ & $28.2(35 / 124)$ & 0.77 \\
\hline Severe bleeding complications & $11.4(27 / 236)$ & $16.2(18 / 111)$ & $7.2(9 / 125)$ & 0.040 \\
\hline AKI & $11.0(26 / 235)$ & $14.6(16 / 110)$ & $8.0(10 / 125)$ & 0.14 \\
\hline Blood transfusion & $44.8(108 / 241)$ & $55.3(63 / 114)$ & $35.4(45 / 127)$ & 0.003 \\
\hline $\begin{array}{l}\text { Echocardiographic aortic regurgitation } \\
\text { (moderate to severe) }\end{array}$ & $14.8(37 / 250)$ & $12.0(14 / 117)$ & $17.3(23 / 133)$ & 0.29 \\
\hline Mitral regurgitation (moderate to severe) & $20.6(43 / 208)$ & $23.6(25 / 106)$ & $17.6(18 / 102)$ & 0.19 \\
\hline In-hospital mortality & $5.4(15 / 277)$ & $6.8(9 / 132)$ & $4.2(6 / 143)$ & 0.43 \\
\hline
\end{tabular}

\footnotetext{
AF - atrial fibrillation, AKI - acute kidney injury, BAV - balloon aortic valvuloplasty, CKI-AKI - contrast induced acute kidney injury, MI-myocardial infarction.
} 
all procedures were performed in the hybrid room and the remaining $42.6 \%$ were performed in the cardiac catheterization laboratory. However, the surgical incision to obtain the femoral access was more frequently performed in women, although it did not translate into a different rate of puncture site complications. The self-expanding Medtronic CoreValve was the most prevalent valve regardless of the gender, but it was significantly less frequently implanted in women than in men. The overall implantation success rate was not different between genders and success was achieved in $96.8 \%$ overall with only 2 female cases requiring bailout surgery.

The course of the initial hospitalization was relatively similar between the genders and the rates of periprocedural MI or stroke were very low and comparable. The only differences were found in the permanent pacemaker (PPM) implantation rate due to conduction disturbances and severe bleeding complications. PPM implantation was necessary almost twice less frequently in women than in men and the rate of severe bleedings along with the necessity for blood transfusion was significantly higher in women than in men. Nonetheless, in-hospital mortality was numerically higher in women than in men (6.8\% vs. $4.2 \%, p=0.43)$.

At discharge, the average NT-proBNP decreased significantly only in women (median reduction by $24.1 \%$ ) in comparison with its values before the procedure (Table III). Moreover, the results of the 6-minute walk test decreased by a median of $13.2 \%$ and the distance covered after the procedure was significantly shorter in women than in men. There was no difference in the duration of hospital stay between the genders.

There primary endpoint of the study - 12-month allcause mortality - occurred in $13.6 \%$ of women and $7.7 \%$ of men ( $p=0.12$, Table IV, Figure 1). Moreover, there were no significant differences in the all-cause mortality and NYHA functional class status at 3-month and 6-month follow-up (Table IV).

\section{Discussion}

The main findings of our study can be described as follows: 1) During the course of more than 10 years there were significant differences in the clinical and periprocedural characteristics between male and female patients. 2) Women undergoing TAVI in our centre are older, less often smokers, but have higher LVEF and have less frequently undergone CABG in the past. 3) The overall implantation success rate was high in both women and men. 4) Despite the lower rate of pacemaker implantation but higher risk of bleeding or the necessity for blood transfusion in women, the 1-year mortality did not differ significantly between the genders.

The subject of differences in the clinical profile and outcomes in cardiovascular disease has seen a renaissance in recent years, with the emergence of studies suggesting that not only are women significantly underrepresented in most CV trials and registries, but also the female gender is associated with different outcomes than their male counterparts $[15,16]$. However, in the PARTNER and PARTNER2 randomized trials conducted in respectively high and intermediate surgical risk, the populations were well balanced, and the percentage of both genders was around 50\% [2, 3]. The reason for an acceptable prevalence of women in the TAVI trials is the specific differences in the pathophysiology of AS between genders. In women, aortic stenosis and increased afterload of the left ventricle result more in its hypertrophy than dilation as in men [17]. Moreover, women with AS tend to maintain preserved ejection fraction, while it undergoes reduction in men. The difference in LVEF between women and men was $6 \%$, which is consistent with the pathophysiological considerations discussed above. On the other hand, more advanced age, lower body surface area and smaller $\mathrm{AV}$ dimensions in women result in technical challenges, which could potentially increase the risk of adverse events in women.

Female gender is considered as a risk factor of higher mortality in both the STS and the EuroSCORE classifications. In contrast, the results of the PARTNER A trial and meta-analysis by Panoulas et al. indicate that in the randomized trials, female gender is associated with a lower mortality in 1-year or 2-year follow-up [18, 19].

Table III. Discharge value of NT-proBNP and 6-minute walk test results according to gender

\begin{tabular}{|c|c|c|c|c|}
\hline Discharge data & Overall & Women & Men & $P$-value (women vs. men) \\
\hline $\begin{array}{l}\text { NT-proBNP }[\mathrm{pg} / \mathrm{ml}] \\
\text { median }[\mathrm{Q} 1-\mathrm{Q} 3]\end{array}$ & $\begin{array}{c}1719.0[809.4-3322.0] \\
(173 / 275)\end{array}$ & $\begin{array}{c}1288.0[686.0-2479.0] \\
(75 / 132)\end{array}$ & $\begin{array}{c}1961.0[908.0-4603.0] \\
(96 / 143)\end{array}$ & 0.007 \\
\hline $\begin{array}{l}\text { Versus before the } \\
\text { procedure }\end{array}$ & $\begin{array}{c}\text { Median reduction by } \\
15.8 \%, p=0.005\end{array}$ & $\begin{array}{c}\text { Median reduction by } \\
24.1 \%, p=0.003\end{array}$ & $\begin{array}{c}\text { Median reduction by } \\
13.8 \%, p=0.21\end{array}$ & \\
\hline $\begin{array}{l}\text { 6MWT }[\mathrm{m}], \text { median } \\
{[\mathrm{Q} 1-\mathrm{Q} 3]}\end{array}$ & $\begin{array}{c}212.8[124.8-305.0] \\
(177 / 275)\end{array}$ & $\begin{array}{c}167.0[99.0-255.0] \\
(77 / 132)\end{array}$ & $\begin{array}{c}252.0[163.0-316.0] \\
(100 / 143)\end{array}$ & $<0.0001$ \\
\hline $\begin{array}{l}\text { Versus before the } \\
\text { procedure }\end{array}$ & $\begin{array}{c}\text { Median reduction by } \\
13.6 \%, p=0.12\end{array}$ & $\begin{array}{c}\text { Median reduction by } \\
11.6 \%, p=0.52\end{array}$ & $\begin{array}{c}\text { Median reduction by } \\
11.3 \%, p=0.16\end{array}$ & \\
\hline $\begin{array}{l}\text { Hospitalization duration, } \\
\text { median [Q1-Q3] }\end{array}$ & $7[5-13](275 / 275)$ & 7 [5-14] (132/132) & 7 [4-13] (143/143) & 0.21 \\
\hline
\end{tabular}

$N T$-proBNP - N-terminal pro b-type natriuretic peptide, 6-MWT-6-minute walk test. 
Table IV. Short- and mid-term outcomes after TAVI according to gender

\begin{tabular}{|c|c|c|c|c|}
\hline Post-discharge outcomes & Overall & Women & Men & $\begin{array}{c}P \text {-value } \\
\text { (women vs. } \\
\text { men) }\end{array}$ \\
\hline \multicolumn{5}{|l|}{30 days, $\%(n / N)$ : } \\
\hline All-cause mortality & $7.3(20 / 275)$ & $9.1(12 / 132)$ & $5.6(8 / 143)$ & 0.35 \\
\hline \multicolumn{5}{|l|}{ NYHA functional class: } \\
\hline I & $13.8(29 / 210)$ & $13.4(13 / 97)$ & $14.2(16 / 113)$ & 0.22 \\
\hline II & $64.8(136 / 210)$ & $67.3(65 / 97)$ & $61.9(70 / 113)$ & \\
\hline III & $19.1(40 / 210)$ & $22.7(22 / 97)$ & $15.9(18 / 113)$ & \\
\hline IV & $1.9(4 / 210)$ & $2.1(2 / 97)$ & $1.8(2 / 113)$ & \\
\hline Readmission due to CVD & $24.4(40 / 164)$ & $26.9(21 / 78)$ & $22.1(19 / 86)$ & 0.58 \\
\hline \multicolumn{5}{|l|}{6 months, $\%(n / N)$ : } \\
\hline All-cause mortality & $9.1(25 / 275)$ & $11.4(15 / 132)$ & $7.0(10 / 143)$ & 0.22 \\
\hline \multicolumn{5}{|l|}{ NYHA class: } \\
\hline I & $25.2(36 / 143)$ & $19.4(13 / 67)$ & $30.3(23 / 76)$ & 0.049 \\
\hline 11 & $55.9(80 / 143)$ & $53.7(36 / 67)$ & $57.8(44 / 76)$ & \\
\hline III & $18.2(26 / 143)$ & $25.4(17 / 67)$ & $11.8(9 / 76)$ & \\
\hline IV & $0.7(1 / 143)$ & $1.5(1 / 67)$ & $0(0 / 76)$ & \\
\hline \multicolumn{5}{|l|}{12 months, $\%(n / N)$ : } \\
\hline All-cause mortality & $10.5(29 / 275)$ & $13.6(18 / 132)$ & $7.7(11 / 143)$ & 0.12 \\
\hline \multicolumn{5}{|l|}{ NYHA class: } \\
\hline I & $31.7(33 / 104)$ & $31.9(15 / 47)$ & $31.6(18 / 57)$ & 0.73 \\
\hline$\|$ & $56.7(59 / 104)$ & $55.3(26 / 47)$ & $57.9(33 / 57)$ & \\
\hline$\overline{I I I}$ & $8.7(9 / 104)$ & $10.6(5 / 47)$ & $7.0(4 / 57)$ & \\
\hline IV & $2.9(3 / 104)$ & $2.1(1 / 47)$ & $3.5(2 / 57)$ & \\
\hline
\end{tabular}

CVD - cardiovascular disease, NYHA - New York Heart Association.

Nonetheless, there are a few important factors requiring attention as far as our study is concerned. First, our population reflects real-world patients, who were deemed inoperable or at prohibitive risk and thus in the majority of cases TAVI was performed as the ultimate treatment modality, not the method of choice or effect of randomization. In that context, the 10.5\% 1-year mortality of patients with low LVEF and multiple comorbidities is worth noting.

The expansion of the transcatheter-delivered aortic valve compresses the atrioventricular conduction system, which can impair the atrio-ventricular conduction and result in the necessity for a PPM implantation [20, 21]. Although persistent "barotrauma" caused by the deployed valve constantly compressing the conduction system can trigger conduction abnormalities in the longterm follow-up, the majority of pacemakers after TAVI are implanted in the first days after the procedure [22].



Figure 1. Kaplan-Meier curves displaying 1-year survival after TAVI according to gender 
In our registry, the PPM implantation rate during the initial hospitalization was almost two-fold lower in women than in men, which is consistent with the studies by Forrest et al. and Buja et al. [23, 24]. Although one cannot exclude other possible explanations of this discrepancy, such as device oversizing or depth of the valve implantation, one has to acknowledge that the self-expandable Medtronic CoreValve and Boston Acurate valves were much more frequently implanted in men than in women. In the prior studies, the utilization of self-expanding valves was associated with an increased risk of post-procedural PPM implantation [25]. Moreover, in the meta-analyses, the Edwards Sapien valve was associated with the lowest rate of post-procedural permanent pacing $[25,26]$.

Last, but not least, the rate of bleeding differed significantly between women and men, with the female patients experiencing severe complications more than twice as often as men. A large meta-analysis encompassing more than 65,000 patients identified female gender as one of the independent risk factors of severe bleeding after TAVI [27]. There are a few explanations of this difference, including the higher rate of transapical access established in women, which has previously been demonstrated to significantly increase the risk of bleeding compared with transfemoral access [28]. Moreover, with a lower body surface area, the diameter of the femoral vessels decreases. Hence, the dimensions of femoral arteries in female patients are significantly lower than in men, which could potentially explain the higher rates of local complications during the establishment of vascular access [29]. Furthermore, in the population included in our study, the vascular access was established surgically in almost twice as many women as in men. It appears that the more minimalistic approach to TAVI, with the utilization of percutaneous femoral access, is associated with fewer vascular complications and lower incidence of bleeding, although the results of the recent Polish analysis from the POL-TAVI registry are in discordance with these results, with a significantly higher incidence of vascular complications in patients in whom percutaneous femoral access was performed [30, 31]. Hence, the other previously determined factors, such as more severe ilio-femoral calcification and tortuosity, lower platelet activity, or other patient- or procedure-related factors, could play a role in higher incidence of bleeding complications in women [32].

This study has a few major limitations one has to be aware of. First of all, the data are derived from the single-centre registry of a tertiary cardiovascular hospital; therefore wide generalization of those data should be performed with caution as the selection of patients for TAVI could exert a significant bias at baseline. Second, although the data have been painstakingly gathered, of the 382 subjects who underwent TAVI throughout the analysed period, the detailed characteristics were available in 275 (71.9\%) patients, as the registry has been voluntarily filled by the individual physicians performing the procedure, and then performing the follow-up visits in the outpatient clinic. Thus, the inclusion of a limited number of patients could potentially influence some results as well. Third, due to the retrospective nature of our analysis, the cause of any association cannot be ascertained, and therefore the data can be considered only as hypothesis-generating. Finally, as the registry reflects real-world practice, the adverse events were not adjudicated by any external institution.

\section{Conclusions}

In this single-centre registry, the rates of all-cause mortality were similar in female and male patients. Female patients were older but less burdened with cardiovascular risk factors than men, but the procedural success rate was very high regardless of gender. Despite differences in permanent pacemaker implantation rate, risk of severe bleeding or necessity for blood transfusion between genders, the 12-month outcomes after TAVI were similar between women and men, although there was a trend for higher all-cause mortality in women.

\section{Conflict of interest}

The authors declare no conflict of interest.

\section{References}

1. Cribier A, Eltchaninoff $H$, Bash A, et al. Percutaneous transcatheter implantation of an aortic valve prosthesis for calcific aortic stenosis: first human case description. Circulation 2002; 106: 3006-8.

2. Smith CR, Leon MB, Mack MJ, et al. Transcatheter versus surgical aortic-valve replacement in high-risk patients. N Engl J Med 2011; 364: 2187-98.

3. Leon MB, Smith CR, Mack MJ, et al. Transcatheter or surgical aortic-valve replacement in intermediate-risk patients. N Engl J Med 2016; 374: 1609-20.

4. Popma JJ, Deeb GM, Yakubov SJ, et al. Transcatheter aortic-valve replacement with a self-expanding valve in low-risk patients. N Engl J Med 2019; 380: 1706-15.

5. Cahill TJ, Chen M, Hayashida K, et al. Transcatheter aortic valve implantation: current status and future perspectives. Eur Heart J 2018; 39: 2625-34.

6. O'Connor SA, Morice MC, Gilard M, et al. Revisiting sex equality with transcatheter aortic valve replacement outcomes: a collaborative, patient-level meta-analysis of 11,310 patients. J Am Coll Cardiol 2015; 66: 221-8.

7. Doshi R, Shlofmitz E, Meraj P. Comparison of outcomes and complications of transcatheter aortic valve implantation in women versus men (from the National Inpatient Sample). Am J Cardiol 2018; 121: 73-7.

8. Bagienski M, Tokarek T, Wiktorowicz A, et al. Sex-related differences in clinical outcomes and quality of life after transcatheter aortic valve implantation for severe aortic stenosis. Adv Interv Cardiol 2017; 13: 233-9. 
9. Chodór P, Wilczek K, Włoch $t$, et al. Impact of coronary artery disease on outcomes of severe aortic stenosis treatment with transcatheter aortic valve implantation. Adv Interv Cardiol 2019; 15: 167-75.

10. Chodór P, Wilczek K, Przybylski R, et al. Impact of CoreValve size selection based on multi-slice computed tomography on paravalvular leak after transcatheter aortic valve implantation. Cardiol J 2017; 24: 467-76.

11. Wacławski J, Wilczek K, Hudzik B, et al. Aortic balloon valvuloplasty as a bridge-to-decision in patients with aortic stenosis. Adv Interv Cardiol 2019; 15: 195-202.

12. Chodór P, Wilczek K, Zielińska T, et al. Assessment of cardiovascular function following transcatheter aortic valve implantation based on six-minute walk test. Cardiol J 2017; 24: 167-75.

13. Wilczek K, Chodór P, Laborde JC, et al. Percutaneous transfemoral aortic CoreValve $(\mathrm{R})$ implantations in high risk patients: another Polish good experience. Kardiol Pol 2009; 67: 1162-5.

14. Kappetein AP, Head SJ, Généreux P, et al. Updated standardized endpoint definitions for transcatheter aortic valve implantation: the Valve Academic Research Consortium-2 consensus document. J Am Coll Cardiol 2012; 60: 1438-54.

15. Steg PG, Bhatt DL, Simon T, et al. Ticagrelor in patients with stable coronary disease and diabetes. N Engl I Med 2019; 381: 1309-20.

16. Berger JS, Elliott L, Gallup D, et al. Sex differences in mortality following acute coronary syndromes. JAMA 2009; 302: 874-82.

17. Piro M, Della Bona R, Abbate A, et al. Sex-related differences in myocardial remodeling. J Am Coll Cardiol 2010; 55: 1057-65.

18. Panoulas VF, Francis DP, Ruparelia N, et al. Female-specific survival advantage from transcatheter aortic valve implantation over surgical aortic valve replacement: meta-analysis of the gender subgroups of randomised controlled trials including 3758 patients. Int J Cardiol 2018; 250: 66-72.

19. Williams M, Kodali SK, Hahn RT, et al. Sex-related differences in outcomes after trans- catheter or surgical aortic valve replacement in patients with severe aortic stenosis: insights from the PARTNER Trial (Placement of Aortic Trans- catheter Valve). J Am Coll Cardiol 2014; 63: 1522-8.

20. Wilczek K, Reguła R, Bujak K, et al. Conduction disturbances after transcatheter aortic valve implantation procedures - predictors and management. Adv Interv Cardiol 2016; 12: 203-11.

21. Rodés-Cabau J, Ellenbogen KA, Krahn AD, et al. Management of conduction disturbances associated with transcatheter aortic valve replacement: JACC Scientific Expert Panel. J Am Coll Cardiol 2019; 74: 1086-106.

22. Schoechlin S, Jalil F, Blum T, et al. Need for pacemaker implantation in patients with normal QRS duration immediately after transcatheter aortic valve implantation. Europace 2019; 21: 1851-6.

23. Forrest JK, Adams DH, Popma JJ, et al. Transcatheter aortic valve replacement in women versus men (from the US CoreValve Trials). Am J Cardiol 2016; 118: 396-402.

24. Buja P, Napodano M, Tamburino C, et al. Comparison of variables in men versus women undergoing transcatheter aortic valve implantation for severe aortic stenosis (from Italian Multicenter CoreValve registry). Am J Cardiol 2013; 111: 88-93.

25. van Rosendael PJ, Delgado V, Bax JJ. Pacemaker implantation rate after transcatheter aortic valve implantation with early and new-generation devices: a systematic review. Eur Heart J 2018; 39: 2003-13.
26. Elgendy IY, Gad MM, Mahmoud AN, et al. Meta-analysis comparing outcomes of self-expanding versus balloon-expandable valves for transcatheter aortic valve implantation. Am J Cardiol 2020; 128: 202-9.

27. Sun Y, Liu X, Chen Z, et al. Meta-analysis of predictors of early severe bleeding in patients who underwent transcatheter aortic valve implantation. Am J Cardiol 2017; 120: 655-61.

28. Wang J, Yu W, Jin Q, et al. Risk factors for post-TAVI bleeding according to the varc-2 bleeding definition and effect of the bleeding on short-term mortality: a meta-analysis. Can J Cardiol 2017; 33: 525-34.

29. Hayashida K, Morice MC, Chevalier B, et al. Sex-related differences in clinical presentation and outcome of transcatheter aortic valve implantation for severe aortic stenosis. J Am Coll Cardiol 2012; 59: 566-71.

30. McCabe JM, Huang PH, Cohen DJ, et al. Surgical versus percutaneous femoral access for delivery of large-bore cardiovascular devices (from the PARTNER Trial). Am J Cardiol 2016; 117: 1643-50.

31. Walas RL, Kukulski L, Rychter J, et al. Vascular access site complications after transfemoral transcatheter aortic valve implantation in the POL-TAVI Registry: surgical versus percutaneous approach. J Cardiovasc Surg 2020; 61: 117-22.

32. Naoum C, Blanke P, Dvir D, et al. Clinical outcomes and imaging findings in women undergoing TAVR. JACC Cardiovasc Imaging 2016; 9: 483-93. 